\title{
Clinical Pharmacy Education and Practice in Nepal: A Glimpse into Present Challenges and Potential Solutions
}

This article was published in the following Dove Press journal:

Advances in Medical Education and Practice

\author{
Sunil Shrestha $\mathbb{D}^{1,2}$ \\ Deepa Shakya ${ }^{1,3}$ \\ Subish Palaian (iD) \\ 'Department of Pharmaceutical and \\ Health Service Research, Nepal Health \\ Research and Innovation Foundation, \\ Lalitpur, Nepal; ${ }^{2}$ Department of \\ Pharmacy, Nepal Cancer Hospital and \\ Research Center Pvt. Ltd, Harisiddhi, \\ Lalitpur, Nepal; ${ }^{3}$ Department of \\ Pharmacy, Norvic International Hospital, \\ Thapathali, Kathmandu, Nepal; \\ ${ }^{4}$ Department of Clinical Sciences, College \\ of Pharmacy and Health Sciences, Ajman \\ University, Ajman, United Arab Emirates
}

Correspondence: Sunil Shrestha Email sunilcresta@gmail.com

\begin{abstract}
This commentary article highlights the challenges in providing clinical pharmacy education in Nepal and suggests a few ways forward. Contrary to other health care professions, clinical pharmacy practice is a new healthcare discipline in the country which is currently undergoing transition. The existing pharmacy curriculum and training in the country can provide competencies needed for pharmacists in industrial settings. Considering the importance of clinical pharmacists in patient care, the Government of Nepal has implemented a policy recommending the recruitment of clinical pharmacists in hospitals. However, the education and training for pharmacists provided in the country are not sufficient enough for optimum patient care and for delivering clinical pharmacy services. International collaborations in terms of faculty and student exchanges, preceptor training, and accreditation by international organizations such as Accreditation Council for Pharmacy Education (ACPE), establishment of need-based curriculum, incorporating clinical pharmacy department under the organizational structure of hospitals, etc., may be the right approaches to improve the current status of clinical pharmacy education in the country.
\end{abstract}

Keywords: clinical pharmacy education, clinical pharmacist, clinical pharmacy practice, clinical pharmacy service, Nepal, pharmacy education

\section{Introduction}

The American College of Clinical Pharmacy (ACCP) defines clinical pharmacy as "a health science discipline in which pharmacists provide patient care that optimizes medication therapy and promotes health, wellness, and disease prevention". "The primary work of clinical pharmacists is to collaborating with other healthcare professionals mainly with doctors and nurses, interviewing the patients for assessment, monitoring of drug therapy responses by patients, give drug information to patients or even to healthcare teams and make explicit therapeutic suggestions to patients. ${ }^{2}$ Currently, clinical pharmacy services are implemented in various countries. However, the area of clinical pharmacy practice is still primitive in the context of Nepal and the Nepalese pharmacy sector is experiencing changes related to clinical pharmacy education and practice.

Nepal is a South Asian nation located between Indian and China with a population of approximately 30 million. $^{3}$ Health care system of Nepal is managed by The Ministry of Health and Population (MOHP) of the Government of Nepal and is in authority for health policy development, planning, and healthcare delivery. ${ }^{4}$ In the recent past, there has been an increase in the number of private hospitals with specialty services and more bed strengths. ${ }^{5}$ The establishment of the 
hospitals inside the country has reduced the outflow of Nepalese patients traveling to India or foreign countries seeking advanced health care services. These private hospitals and few government-run hospitals employ pharmacists and assistant pharmacists who often manage the hospital pharmacy. Pharmacists working in hospital pharmacy are expected to provide clinical pharmacy services as well. However, in a lack of competency and expertise, they are unable to deliver appropriate clinical pharmacy services at their workplace.

Usually, the pharmacists in Nepal complete their formal education on clinical pharmacy either within the country or from the nearby countries, India, Pakistan, and Bangladesh, where also the clinical pharmacy practice is not well established. In Nepal, the quality delivery of pharmacy education is managed by the Nepal Pharmacy Council (NPC), through regular inspection visits and the NPC is responsible for the registration of qualified pharmacists and assistant pharmacists. ${ }^{6}$ A pharmacist and assistant pharmacist must register in the NPC to have a professional license to practice pharmacy in the country. ${ }^{6}$ Even while a registered pharmacist from the country applies for a job abroad, the council provides verification services for foreign job applicants.

As of 2020, there are 3761 pharmacists and 7162 pharmacy assistants registered with the NPC. ${ }^{6}$ Nevertheless, the pharmacists with aMaster in Pharmacy (Pharmaceutical Care), Master's degree in Clinical Pharmacy and Doctor of Pharmacy (Post-baccalaureate), are not recognized as clinical pharmacists or hospital pharmacists, or other title or designation by the council as there is no provision and stringent policies for the subdivision of the pharmacists. Also, though the theoretical and practical concept of clinical pharmacy is provided in the undergraduate and graduate study as per the requirement of the respective syllabus, the actual required skill and knowledge regarding the clinical pharmacy seem lacking among the pharmacy graduates.

\section{Emerging Role of Clinical Pharmacy Practice}

The emergence of clinical pharmacy services in the hospital lead pharmacists to be more patient-oriented in addition to the traditional dispensing services. Clinical pharmacy practice was initially established in developed countries such as the United States (US) and most of the European countries. However, the situation is not the same in low- and middle-income nations, Latin America, Africa, Asia, and the Middle East. It is more likely to occur in the developing world where health care systems are also not well established/supported. Currently, in developing countries such as Nepal, Pakistan, India and Bangladesh, and many African countries clinical pharmacy is practiced in fewer hospitals, with varying success. ${ }^{7,8}$ Clinical pharmacy service is provided by the pharmacist who possesses specialized advanced education and training and works in collaboration with other health care professionals. ${ }^{9}$ The overall objective of clinical pharmacy practice is to provide an organized, complete and constant quality of facility to every single patient. $^{10}$

\section{Clinical Pharmacy Practice in Nepalese Context}

In Nepal, majority of hospitals (including both private and government-run) have established hospital pharmacy services in the country. The service was first initiated by Santabhavan Hospital (presently known as Patan Hospital) in the year 1956. It was then followed by other government hospitals, i.e Tansen Mission hospital, Kanti Hospital and Bir Hospital. Similarly, non-government hospitals like Dhulikhel Hospital (Kavre), Manipal Teaching Hospital (Pokhara), Kathmandu Model Hospital (Kathmandu) started the hospital pharmacy practice providing quality care to patients. ${ }^{11}$ In the recent past, few other private hospitals such as the College of Medical Sciences-Teaching Hospital in Bharatpur, Nepal Cancer Hospital and Research Center and Mediciti Hospital and Nepal Mediciti Hospital in Lalitpur, Grande International Hospital, Nepal Medical College and Teaching hospital and Norvic International Hospital in Kathmandu have started incorporating clinical pharmacy services. However, the clinical pharmacists engaged in these hospitals providing clinical pharmacy services are low in number. Clinical pharmacists are also involved in activities such as procurement, distribution, store management and other activities predominantly related to hospital pharmacy services. In Nepal, core clinical pharmacy services are either lacking or being provided with limited expertise to a limited number of patients or units in the hospital where the physicians voluntarily opt for it and encourage pharmacists to perform their clinical duties. The provision of the pharmaceutical care plan by pharmacists is nonexistent currently. In the year 2015, 'Hospital Pharmacy Guideline 2072 ' which was developed by the Ministry of Health and Population (MOHP), suggested that hospitals with 51-100 beds should have one clinical pharmacist to provide clinical pharmacy services, ${ }^{12}$ which seemed to be a ray of hope for recognition of clinical pharmacy services in the country. However, this guideline has not been implemented effectively 
in all the hospitals within the country, more so common in the government-run hospitals.

As the concept of clinical pharmacy is slowly being recognized in the country, there are fair chances of shaping the career of clinical pharmacists in government or private organizations. Currently, PharmD graduates and M. Pharm degree holders from different universities are working in hospital pharmacies as managers and faculty in medical and pharmacy institutes and rarely practicing as clinical pharmacists in private tertiary care hospitals. However, one must admit that the remuneration for the practicing clinical pharmacists is far too low and thus encouraging pharmacists either to look for a job in Middle east countries or sectors other than clinical pharmacy wherein the salary is better at least.

\section{Current Status of Clinical Pharmacy Practice in Nepal}

Clinical pharmacy services witness several challenges despite their importance in improving patient outcomes. There are several problems which are associated with pharmacy education (curriculum content, manpower, and infrastructure $^{13}$ and issues related to the practice environment). Challenges also arise from the poor awareness among the general public, attitude of pharmacists, and communication gaps between pharmacists. ${ }^{14}$ Besides these, lack of continuity of services, undefined roles and responsibilities of pharmacists in hospitals, poor recognition and unacceptance by other health care professionals are the challenges faced by the clinical pharmacist. The prospects and opinions of doctors towards the roles and responsibilities of pharmacists are the key factors that influence the development of clinical pharmacy services in hospitals.

\section{Potential Clinical Pharmacy Focus Areas in Nepal}

With increased in various general and specialty hospitals, there is an emerging scope for clinical pharmacy services in the country. Pharmacists can play an important role in identifying, preventing, and mitigating drug therapyrelated problems and can stand as a pharmaceutical care providers for the patients. A few of the potential clinical pharmacy areas that can be focused by pharmacists in Nepal are listed in Table 1.

\section{Challenges in Implementing Clinical Pharmacy Services in Nepal}

One of the key concerns associated with implementing clinical pharmacy services in hospitals of Nepal is the de-prioritization by the government. However, only a few non-government hospitals in Nepal have implemented clinical pharmacy services. However, there are a possible number of challenges in the implementation of clinical pharmacy services in every government and private hospitals in Nepal. These factors are related to pharmacy policy, pharmacist and adoption by other healthcare professionals and hospital management related factors.

\section{Clinical Pharmacy Education and Challenges in Providing Clinical Pharmacy Education in Nepal}

In 1972, the Institute of Medicine (IOM) in Nepal established pharmacy education with the program called Intermediate in Pharmacy (similar to a diploma in pharmacy degree). Later, in 1994, Kathmandu University (Dhulikhel) started a Bachelor of Pharmacy (B. Pharm) program and the same program was consecutively started at IOM (Tribhuvan University), Pokhara University (Pokhara) and Purbanchal University (Biratnagar). Kathmandu University was the first university to introduce a pharmacy practice course in its Masters in Pharmacy (M. Pharm) curriculum, called "Pharmaceutical Care" in the year 2000 to provide a patient-oriented pharmacy education. This was later replaced by 3 years postbaccalaureate Doctor of Pharmacy (Pharm D) course in 2010-2015. The PharmD program had faced multiple challenges ${ }^{13}$ and was paused in 2015 . However, the performance of PharmD graduates from 2012 to 2015 and the university was never evaluated. The NPC performs annual inspection visits to universities and colleges ensuring the quality delivery of the pharmacy educational program. The Kathmandu University restarted its Masters in Pharmacy (pharmaceutical care) program from 2015 onwards. In addition to this, M. Pharm program, other universities of Nepal i.e, Pokhara and Purbanchal Universities started 2 years of Masters in Clinical Pharmacy program in the year 2011 and 2016 respectively, all focusing on patient-oriented curricula. In 2017, private college CIST College, affilitaed to Pokhara University also started Masters in Clinical Pharmacy program. Bachelor of pharmacy programs are offered by a total of 19 institutions, Diploma in Pharmacy is offered by around 29 colleges and a Master in Pharmacy program is provided by 3 universities. ${ }^{6}$ Besides the central colleges under respective 
Table I Priority Clinical Pharmacy Areas Requiring Trained Pharmacists

\begin{tabular}{|c|c|}
\hline Clinical Pharmacy Areas & Comments \\
\hline Antimicrobial stewardship & $\begin{array}{l}\text { Irrational use of antimicrobials is a common problem in the country and very few hospitals have antimicrobial } \\
\text { stewardship programs. }{ }^{15} \text { This can be an important area for clinical pharmacists to focus on. Initially, intensive care } \\
\text { units may be a focal point. }\end{array}$ \\
\hline Critical care services & $\begin{array}{l}\text { Critical care settings involving complex pharmacotherapeutic regimens can be a potential beneficiary from clinical } \\
\text { pharmacy services. }\end{array}$ \\
\hline $\begin{array}{l}\text { Dosage adjustment in special } \\
\text { populations }\end{array}$ & $\begin{array}{l}\text { Currently, there are } 32 \text { hospitals in Nepal which provide a free dialysis services. This services run under the } \\
\text { Ministry of Health and Population (Government of Nepal). }{ }^{4} \text { Pharmacists are required for dosage adjustments in } \\
\text { patients with renal failures and other related issues at these centers. Also, hospitals having more patient load of } \\
\text { hepatic failure patients, children and elderly people should have pharmacists working for better dose } \\
\text { management of the prescribed medications. }\end{array}$ \\
\hline Drug information services & $\begin{array}{l}\text { There are poorly resourced drug information services in the country. Pharmacists with skills in the provision of } \\
\text { drug information services are needed. }{ }^{16}\end{array}$ \\
\hline Drug-drug interactions (DDIs) & The clinical pharmacists can help identify potential DDIs and prevent them from occurring in the patients. ${ }^{17}$ \\
\hline Drug utilization evaluation & $\begin{array}{l}\text { Drug utilization research can improve drug use processes in hospitals and the community }{ }^{18} \text { To begin with, clinical } \\
\text { pharmacists can focus on drug utilization in hospitals and medicine use in specialty areas. }\end{array}$ \\
\hline Emergency department service & $\begin{array}{l}\text { In Nepal, there is no clinical pharmacist or pharmacist involved in the emergency departments of hospitals. This } \\
\text { is an important section where the clinical pharmacist has a greater role to play. }\end{array}$ \\
\hline Medication reconciliation & $\begin{array}{l}\text { There are studies highlighting medication errors, adverse drug reactions (ADRs) occurring in the country. There } \\
\text { can be a great scope for pharmacists in providing medication reconciliation services to the patients. }{ }^{19}\end{array}$ \\
\hline Medication error assessment & $\begin{array}{l}\text { There have been reports on the occurrence of medication errors. }{ }^{20} \text { The involvement of skilled clinical } \\
\text { pharmacists in assessing and addressing medication errors can decrease its occurrence to a greater extent. }\end{array}$ \\
\hline Oncology pharmacy practice & $\begin{array}{l}\text { Pharmacists have been known to provide clinical pharmacy services in oncology departments. }{ }^{21} \text { Additional } \\
\text { clinical pharmacists are needed to enhance better patient outcomes. }\end{array}$ \\
\hline Patient counseling services & $\begin{array}{l}\text { Various studies have revealed the existence of patient counseling services in Nepal. }{ }^{16} \text { However, this has not been } \\
\text { endorsed by all the hospitals thereby creating a gap to be fulfilled by clinical pharmacists. }\end{array}$ \\
\hline Pharmacovigilance & $\begin{array}{l}\text { The country has established national pharmacovigilance program and currently has } 12 \text { regional pharmacovigilance } \\
\text { centers. }{ }^{22} \text { There is a scope for clinical pharmacy practitioners in ADR reporting, causality assessment and other } \\
\text { aspects at each regional pharmacovigilance centers. }\end{array}$ \\
\hline $\begin{array}{l}\text { Therapeutic drug monitoring } \\
\text { (TDM) }\end{array}$ & $\begin{array}{l}\text { This is a another possible area of clinical pharmacy services which is not explored properly in Nepal. Clinical } \\
\text { pharmacist led-TDM program can be initiated. }\end{array}$ \\
\hline
\end{tabular}

universities, various pharmacy colleges hold affiliation of Tribhuvan University, Kathmandu University, Pokhara University, Purbanchal University, and the Council for Technical Education and Vocational Training (CTEVT). ${ }^{14}$

In 2003, NPC has adopted Guidelines for the Accreditation of Pharmacy Degree Programmes. ${ }^{23}$ With the vision of setting pharmacy practice standards and uplifting the pharmacy professionals' structure, licensure examination for pharmacists and pharmacy assistants was then implemented by NPC. ${ }^{6}$ The pharmacists and pharmacy assistants are considered as registered, once they clear the licensure exam which is taken by NPC. ${ }^{14}$ Unlike for pharmacist and assistant pharmacy, NPC has not conducted licensure examination for the Masters degree program (clinical pharmacy and industrial pharmacy).

Like any other developing country, pharmacy education in Nepal was traditionally more product-oriented but it's focus is currently shifting towards direct patient care as well. Though there have been attempts to convert pharmacy education to be patient-oriented, the transition is highly turbulent and had noticed several lacunae due to a lack of integration of practice standards across different 
settings. ${ }^{24}$ Rather than a patient-oriented health care professional, Pharmacists in Nepal are more considered as drug sellers in commercial enterprises. The pharmacy graduates after completing their Clinical Pharmacy education either choose a job in pharmaceutical industries, try for foreign jobs or involve in other businesses that are not related to their educational qualifications.

Nepal, being a country with inadequate resources, lacks the infrastructure and manpower for effective pharmaceutical training and to maintain updated curricula. Thereby, for the capacity building approaches, efficient management out frame facilitated by the effective directions and mentorship is very important. ${ }^{25}$ National and international collaborations can be beneficial. The universities should also establish a memorandum of understanding (MoUs) with large hospitals having clinical pharmacy services in providing experiential learning for students. The institutions running the pharmacy programs should stimulate the proper utilization of funds and resources garnered by collaborating with the various interested contributors for the beneficial capacity building in the pharmacy field. ${ }^{26}$

Anderson $\mathrm{C}$ and Futter $\mathrm{B}^{27}$ have argued that a "need-based curriculum rather than focusing on adopting PharmD from developed countries without a proper preparation" is important. Though PharmD was originally designed for North American practice settings it can be implemented with proper experiential learning centers and trained preceptors. ${ }^{13}$

In Nepal, outdated curriculum, and limited resources to explore clinical pharmacy practices remain the major pitfalls in pharmacy education. ${ }^{13}$ Also, pharmacy colleges (including those attached to university campuses) do not have their teaching hospital attached to it which directly influence the exposure of pharmacist to hospital settings. ${ }^{28}$ Some other challenges associated with pharmacy education in the country are mentioned below:

\section{Lack of Interprofessional Education (IPE)}

With the advancement and complexity in health care technology, complicated patient cases, increasing prevalence of chronic disorders made the necessity of inclusion of more than one profession in their care. ${ }^{29}$ The World Health Organization (WHO) has recognized that interprofessional education (IPE) is crucial to integrate care, strengthen the quality and improve patient safety. Different countries such as the UK, US, Germany, Poland, Australia had included IPE in pharmacy curricula. ${ }^{30}$ IPE creates an optimal health care system. Early incorporation of IPE into the curriculum may have the biggest impact on the health care system ${ }^{31}$ as the students and faculties from different health care programs come together to explore the differences and similarities among the various programs. Since IPE is rarely practiced, the graduates have less tendency to work together as a team with other health professionals.

As multi-professional health care teams, clinical pharmacists play a significant role in the delivery of IPE and expanding their clinical roles. ${ }^{32}$

IPE also provides an opportunity for each healthcare students to appreciate each other's strengths and establish a working relationship among these future health professionals. It also allows pharmacists to best communicate recommendations to other health professionals.

\section{Experiential Learning and Clinical Skills Training}

For practicing as a pharmacist or a clinical pharmacist, the development of clinical pharmacy skills is essential. ${ }^{33}$ The skills required for patient-oriented care includes clinical practice, critical thinking, decision-making, collaborative interpersonal practice, and these skills can be built with experiential training. Experiential learning and clinical skills help to produce confident graduates. Further, it makes students capable to assume their responsibilities towards patient care and apply their knowledge and skill in drug therapy management. ${ }^{34}$

\section{Lack of Skills Labs}

No skills lab provides physical assessment skills needed for clinical pharmacists, required for the ones working in ambulatory care centers and community pharmacies. Knowledge of physical assessment is needed for clinical pharmacists to conduct complete and accurate patient evaluations. The pharmacy curriculum should be also revised by adding physical assessments in the current curriculum.

\section{Lack of Clinically Trained Preceptors}

It is important to have trained clinical preceptors who can oversee the experiential learning programs in the practice sites. These preceptors needed to be from hospitals as well as from community pharmacies. The presence of clinically competent preceptors enables students to shadow the preceptors and establish a "role model" for their future job responsibilities. However, currently, such an option is very far from reach in Nepal. 


\section{Lack of Hospitals with Clinical Pharmacy Services}

There are a very limited number of hospitals which provide clinical pharmacy services and providing clinical pharmacy training.

\section{Way Forward}

Despite the challenges, clinical pharmacy is one of the needed services in Nepal. The Center for the Advancement of Pharmacy Education (CAPE) emphasizes the knowledge, skills, abilities, and attitudes are essential to becoming competent and qualified pharmacists in practice. ${ }^{35,36} \mathrm{CAPE}$ outcomes are designed with four domains to guide the institutes in educating pharmacists. These four domains are further divided into 15 subdomains outcome; learner, caregiver, manager, promoter, provider, problem solver, educator, advocate, collaborator, communicator, self-aware, leader, innovator, and professional. These are constructed to identify what students should be capable of upon graduation from the Pharm D program who are practice ready for the profession. ${ }^{31}$ The findings from the study by Alston et al stated that those applicants who did not possess the attributes of CAPE subdomains would not be hired for a job. ${ }^{36}$ Likewise, in Nepal, rigid categories can be made (or the same of CAPE can be followed) which should be satisfied by all the professional pharmacists to be considered as a clinical pharmacist or community pharmacist because the existing pharmacy education and training do not impart all the skills to the future pharmacists. It has become utterly necessary to review and revise the clinical pharmacy curricula and link the course and program learning outcomes with the CAPE outcomes making sure that the students are provided with these essential skills needed for the pharmacists.

Clinical pharmacy-related national guidelines should be developed and executed by the Ministry of Health and Population (MOHP), ${ }^{4}$ Department of Drug Administration (DDA) and $\mathrm{NPC}^{6}$ along with collaborating with all the universities giving clinical pharmacy education, pharmacy organizations of Nepal, hospitals and related stakeholders. The pharmacy curriculum should be revised giving more emphasis the patient-centered pharmaceutical care delivery. Awareness among other health care professionals and hospital management on the importance of clinical pharmacy services should be the starting point of change to achieve excellence in clinical pharmacy practice in Nepal. The gap

Table 2 Strategies to Improve Clinical Pharmacy Education and Training in the Country

\begin{tabular}{|c|c|}
\hline Strategies & Comments \\
\hline $\begin{array}{l}\text { Awareness program targeting other health } \\
\text { professionals }\end{array}$ & $\begin{array}{l}\text { Strategies to be developed to create awareness among other health professionals on the } \\
\text { importance of clinical pharmacy services. }\end{array}$ \\
\hline Creating a job title for clinical pharmacists & $\begin{array}{l}\text { It is also mandatory that the clinical pharmacy department is included in the organizational } \\
\text { structure of hospitals with clear job responsibilities. }\end{array}$ \\
\hline Community engagement activities by the students & $\begin{array}{l}\text { Pharmacists should participate in community engagement activities providing services. } \\
\text { This may be performed on marking various health days such as World Diabetes Day, } \\
\text { World Hypertension day, No tobacco day, Breast cancer awareness, etc. This helps the } \\
\text { general public to know and understand the role of pharmacists. }\end{array}$ \\
\hline Establishment of skills lab & $\begin{array}{l}\text { Physical assessment and other patient care related skills should be provided to the } \\
\text { pharmacists. These skills should be evaluated through the Objective Structured Clinical } \\
\text { Examination (OSCE) and other skills evaluation methods. }\end{array}$ \\
\hline International accreditation & $\begin{array}{l}\text { The Accreditation Council for Pharmacy Education (ACPE) accreditation can provide the } \\
\text { institutes with the required expertise and facilities needed for upgrading the curriculum } \\
\text { and delivery of the programs. }\end{array}$ \\
\hline $\begin{array}{l}\text { International collaboration with institutes offering } \\
\text { established clinical pharmacy programs }\end{array}$ & $\begin{array}{l}\text { These collaborations can be in the form of faculty exchange, preceptor training, } \\
\text { curriculum development, and student exchange programs. Based on the recent } \\
\text { experiences during the COVID-19 pandemic, one can also explore the possibility of } \\
\text { implementing these collaborations through distance learning platforms. }\end{array}$ \\
\hline Licensing provision for clinical pharmacists & $\begin{array}{l}\text { There should be the provision of a licensing exam for PharmD, Masters in Clinical } \\
\text { Pharmacy graduates and the ones who clear the exam should be entitled as practicing } \\
\text { clinical pharmacists. }\end{array}$ \\
\hline
\end{tabular}


between pharmacy practice and academics which should full filled with introducing pharmacy practice-based teaching and learning modules, tying up with hospital and health sectors. ${ }^{37}$

Another major component of continuing professional development is through continuing education. This approach enables pharmacists to acquire the necessary skills and knowledge to remain updated and competent in their practice. Few additional approaches to improve clinical pharmacy education and training are mentioned in Table 2.

\section{Conclusion}

The recognition of clinical pharmacy services by the Government of Nepal indicates that it can be an integral part of health care services within the country. However, as pharmacy education in the country is more oriented towards industry and graduate pharmacists are unable to perform patient care and related clinical pharmacy services in the hospitals, it is a challenging task to uplift the fledgling clinical pharmacy services. The educational institutes should build their capacities for imparting skills to their students and for better experiential training opportunities through qualified and competent clinical preceptors. International collaborations and accreditation of the educational programs for the betterment of the clinical pharmacy may be the way forward.

\section{Acknowledgments}

The authors of this manuscript would like to acknowledge Ms. Asmita Priyadarshini Khatiwada, Nepal Health Research and Innovation Foundation, Nepal for her assistance in revising the manuscript and recommending modifications.

\section{Funding}

The authors received no funding.

\section{Disclosure}

The authors declare no conflict of interest.

\section{References}

1. American College of Clinical Pharmacy. The definition of clinical pharmacy. Pharmacotherapy. 2008;28(6):816-817. doi:10.1592/ phco.28.6.816

2. Wiedenmayer K, Summers RS, Mackie CA, et al. Developing Pharmacy Practice: A Focus on Patient Care: Handbook. World Health Organization; 2006.

3. Worldometer. Nepal Population. Available from: https://www.world ometers.info/world-population/nepal-population/. Accessed June 29, 2020.
4. Ministry of Health and Population. Available from: https://mohp.gov. $\mathrm{np} / \mathrm{en} /$. Accessed July 1, 2020.

5. Government of Nepal. Ministry of HealHealth. Nepal Health Facility Survey 2015. Available from: https://dhsprogram.com/pubs/pdf/ SPA24/SPA24.pdf. 2016. Accessed July 1, 2020.

6. Nepal Pharmacy Council. Available from: https://nepalpharmacycoun cil.org.np/. Accessed July 1, 2020.

7. Azhar S, Hassali MA, Ibrahim MIM, Ahmad M, Masood I, Shafie AA. The role of pharmacists in developing countries: the current scenario in Pakistan. Hum Resour Health. 2009;7(1):54. doi:10.1186/1478-4491-7-54

8. Bilal AI, Tilahun Z, Gebretekle GB, Ayalneh B, Hailemeskel B, Engidawork E. Current status, challenges and the way forward for clinical pharmacy service in Ethiopian public hospitals. BMC Health Serv Res. 2017;17(1):359. doi:10.1186/s12913-017-2305-1

9. Jacobi J. Clinical pharmacists: practitioners who are essential members of your clinical care team. Revista Médica Clínica Las Condes. 2016;27:571-577. doi:10.1016/j.rmclc.2016.09.002

10. Parthasarathi G, Nyfort-Hansen K, Nahata MC. A Text Book of Clinical Pharmacy Practice: Essential Concepts and Skills. Orient Blackswan; 2004.

11. Khanal DP. History of pharmaceutical development in Nepal. $J$ Manmohan Memorial Instit Health Sci. 2017;3(1):86-93. doi:10.3126/jmmihs.v3i1.19182

12. Hospital pharmacy guideline 2072. Kathmandu (Nepal): Government of Nepal, Ministry of Health and Population. Available from: http:// www.dda.gov.np/content/hospital-pharmacy-guideline-2072. Accessed July 1, 2020..

13. Bhuvan KC, Subish P, Mohamed Izham MI. PharmD education in Nepal: the challenges ahead. Am J Pharm Educ. 2011;75(2):38c-38c. doi:10.5688/ajpe75238c

14. Ranjit E. Pharmacy practice in Nepal. Can J Hosp Pharm. 2016;69 (6):493-500. doi:10.4212/cjhp.v69i6.1614

15. Veve MP, Kaljee LM, Prentiss T, et al. Implementing antimicrobial stewardship in two community Nepali Hospitals. Open Forum Infect Dis. 2017;4(Suppl 1):S20-S20. doi:10.1093/ofid/ofx162.051

16. Shrestha S, Khatiwada AP, Gyawali S, Shankar PR, Palaian S. Overview, challenges and future prospects of drug information services in Nepal: a reflective commentary. $J$ Multidiscip Healthc. 2020;13:287. doi:10.2147/JMDH.S238262

17. Sharma S, Chhetri HP, Alam K. A study of potential drug-drug interactions among hospitalized cardiac patients in a teaching hospital in Western Nepal. Indian $J$ Pharmacol. 2014;46(2):152-156. doi:10.4103/0253-7613.129303

18. Shankar PR, Mishra P, Subish P, Upadhyay DK. Can drug utilization help in promoting the more rational use of medicine? Experiences from Western Nepal. Pak J Pharm Sci. 2007;20 (3):243-248.

19. Kadir A, Subish P, Anil K, Ram B. Pattern of potential medication errors in a tertiary care hospital in Nepal. Ind $J$ Pharm Pract. 2010;3:2.

20. Shrestha R, Prajapati S. Assessment of prescription pattern and prescription error in outpatient department at Tertiary Care District Hospital, Central Nepal. J Pharm Pol Pract. 2019;12(1):16. doi:10.1186/s40545-019-0177-y

21. Khanal S, Poudel A, Sharan K, Palaian S. Oncology pharmacy practice in a teaching hospital in Nepal. $J$ Oncol Pharm Pract. 2009;16(2):75-79. doi:10.1177/1078155209337662

22. Department of Drug Administration. Pharmacovigilance. Available from: http://www.dda.gov.np/content/pharmacovigilance. Accessed July $1,2020$.

23. Saha D. Glimpse of pharmaceutical education in Nepal. Int J Pharm Teach Pract. 2013;4(1):438-441.

24. Toklu HZ, Hussain A. The changing face of pharmacy practice and the need for a new model of pharmacy education. $J$ Young Pharm. 2013;5(2):38-40. doi:10.1016/j.jyp.2012.09.001 
25. Konduri N, Rauscher M, Wang S-CJ, Malpica-Llanos T. Individual capacity-building approaches in a global pharmaceutical systems strengthening program: a selected review. J Pharm Pol Pract. 2017;10:16. doi:10.1186/s40545-017-0104-z

26. Lim ZB. Capacity building in pharmacy education in resource-poor settings: an ethnographic case study of Malawi. 2013.

27. Anderson C, Futter B. PharmD or needs based education: which comes first? Am J Pharm Educ. 2009;73(5):92. doi:10.5688/aj730592

28. Ansari M, Alam K. Pharmacy practice in Nepal. In: Pharmacy Practice in Developing Countries. Elsevier; 2016:147-168.

29. Thistlethwaite J. Interprofessional education: a review of context, learning and the research agenda. Med Educ. 2012;46(1):58-70. doi:10.1111/j.1365-2923.2011.04143.x

30. World Health Organization. Framework for Action on Interprofessional Education and Collaborative Practice. World Health Organization; 2010.

31. Patel N, Begum S, Kayyali R. Interprofessional Education (IPE) and Pharmacy in the UK. A study on IPE Activities across Different Schools of Pharmacy. Pharmacy. 2016;4(4):28. doi:10.3390/ pharmacy4040028
32. Pharmacy ACoC, Page RL, Hume AL, et al. Interprofessional education: principles and application a framework for clinical pharmacy. Pharmacotherapy. 2009;29(7):879. doi:10.1592/phco.29.7.879.

33. Ryan M, Shao H, Yang L, et al. Clinical pharmacy education in China. Am J Pharm Educ. 2008;72:6. doi:10.5688/aj7206129

34. Hall K, Musing E, Miller DA, Tisdale JE. Experiential training for pharmacy students: time for a new approach. Can J Hosp Pharm. 2012;65(4):285.

35. Medina MS, Plaza CM, Stowe CD, et al. Center for the advancement of pharmacy education 2013 educational outcomes. Am J Pharm Educ. 2013;77:8. doi:10.5688/ajpe778S8

36. Alston GL, Marsh WA, Castleberry AN, Kelley KA, Boyce EG. Pharmacists' opinions of the value of CAPE outcomes in hiring decisions. Am J Pharm Educ. 2017;81:10. doi:10.5688/ajpe6112

37. Bhuvan KC, Palaian S, Khanal S, Alam K, Khan G, Budhathoki U. History and evolution of pharmaceutical education in Nepal: education versus practice. J Nep Pharma Association. 2017;28(1):12-15.

\section{Publish your work in this journal}

Advances in Medical Education and Practice is an international, peerreviewed, open access journal that aims to present and publish research on Medical Education covering medical, dental, nursing and allied health care professional education. The journal covers undergraduate education, postgraduate training and continuing medical education including emerging trends and innovative models linking education, research, and health care services. The manuscript management system is completely online and includes a very quick and fair peer-review system. Visit http://www.dovepress.com/testimonials.php to read real quotes from published authors. 